Introduction: BEAM (carmustine, etoposide, cytarabine, melphalan) is the most frequently used high-dose chemotherapy regimen for patients with lymphoma referred for autologous haematopoietic cell transplantation (autoHCT). Recently, a novel conditioning protocol containing bendamustine instead of carmustine (BeEAM) has been proposed to potentially increase the efficacy.

Aim of the study: The aim of this study was to retrospectively compare the safety profile of BEAM and BeEAM based on single-centre experience.

Material and methods: A total of 237 consecutive patients with lymphoma treated with either BEAM $(n=174)$ or BeEAM $(n=63)$, between the years 2011 and 2016, were included in the analysis. Clinical characteristics of both groups were comparable. Patients with Hodgkin's lymphoma ( $\mathrm{HL}$ ) constituted $49 \%$ of the BEAM group and $40 \%$ of the BeEAM group.

Results: Median time to neutrophil $>0.5 \times 10^{9} / /$ recovery was 10 days in both groups $(p=0.29)$, while median time to platelet $>50 \times 10^{9} /$ recovery was 13 and 14 days after BEAM and BeEAM, respectively $(p=0.12)$. The toxicity profile was comparable except for arterial hypertension and severe hypokalaemia, which occurred more frequently after BeEAM compared to $\operatorname{BEAM}(p=0.02$ and $p=0.004$, respectively). The rate of early mortality was $1.7 \%$ and $1.6 \%$, respectively. The probabilities of the overall and progression-free survival were comparable for both groups $(p=0.73$ and $p=0.55$, respectively).

Conclusions: Administration of bendamustine instead of carmustine as part of conditioning does not affect the engraftment or the toxicity profile of the regimen. Therefore, BeEAM may be safely used in patients with lymphoma undergoing autoHCT. Its efficacy requires evaluation in prospective studies.

Key words: bendamustine, carmus tine, toxicity, conditioning, lymphoma, autologous haematopoietic cell transplantation.

Contemp Oncol (Pozn) 2018; 22 (2): 113-117 DOI: https://doi.org/10.5114/wo.2018.77046

\section{Comparable safety profile of BeEAM (bendamustine, etoposide, cytarabine, melphalan) and BEAM (carmustine, etoposide, cytarabine, melphalan) as conditioning before autologous haematopoietic cell transplantation}

\author{
Andrzej Frankiewicz, Maria Saduś-Wojciechowska, Jacek Najda, \\ Tomasz Czerw, Włodzimierz Mendrek, Małgorzata Sobczyk-Kruszelnicka, \\ Katarzyna Soska, Małgorzata Ociepa, Jerzy Hołowiecki, Sebastian Giebel
}

Maria Sklodowska-Curie Institute - Cancer Center, Gliwice Branch, Gliwice, Poland

\section{Introduction}

The prognosis of patients with relapsed/refractory (RR) Hodgkin's lymphoma $(\mathrm{HL})$ and non-Hodgkin lymphomas $(\mathrm{NHL})$ treated with conventional-dose salvage regimens is poor. High-dose chemotherapy (HDCT) followed by autologous haematopoietic cell transplantation (autoHCT) is a standard therapeutic option for the majority of chemosensitive RR lymphoma patients. This procedure, being relatively safe (transplant related mortality (TRM) between 1 and 5\%), was demonstrated to improve both overall survival (OS) and progression-free survival (PFS) compared to conventional-dose salvage regimens [1-3]

BEAM (carmustine, etoposide, cytarabine, melphalan) is the most common regimen used as conditioning before autoHCT for patients with RR lymphomas [4]. In order to potentially increase the efficacy [5, 6] and to reduce pulmonary toxicity $[7,8]$, other agents, like thiotepa, lomustine, or bendamustine, have been proposed to replace carmustine (TEAM, CEAM, and BeEAM, respectively) [9-11].

The mechanisms of in vitro cytotoxicity of bendamustine are well described. The mustard group of the particle is responsible for its alkylating activity, while the purine analogue group reveals its antimetabolite activity. It also displays features unrelated to other alkylating agents. It activates DNA-damage stress response and apoptosis. In the case of dysfunction of apoptotic path (e.g. p53 mutation) it also inhibits mitotic checkpoints, which leads to mitotic catastrophe in tumour cells [12]. Bendamustine, unlike other alkylators, activates a base excision DNA repair pathway rather than an alkyltransferase DNA repair mechanism. Moreover, in vitro experiments on cell lines showed that both bendamustine and carmustine potentiate the activity of cytarabine and melphalan [5]. These differences explain the efficacy of bendamustine in patients with relapsed lymphoma refractory to other alkylating agents [12]. The drug has a proven clinical activity in RR lymphoproliferative disorders like chronic lymphocytic leukaemia, multiple myeloma, or indolent lymphomas [13-16].

Although many trials on safety and efficacy profiles of various conditioning regimens have been published $[5,17,18]$, to the best of our knowledge the comparison of BeEAM and BEAM safety profiles has not been reported so far. The aim of this study was to compare both regimens with respect 
to their tolerance and effect on engraftment. Preliminary data regarding their efficacy have also been reported.

\section{Material and methods}

\section{Study design}

This was a retrospective, single-centre study including consecutive patients with either $\mathrm{HL}$ or $\mathrm{NHL}$ treated with HDCT using either BEAM or BeEAM between January 2011 and August 2016. Patients with mantle cell lymphoma as well as those with peripheral T-cell lymphoma, except for anaplastic large cell lymphoma ALK+, had indications for autoHCT in first remission. For other lymphoma subtypes HDCT was considered in cases of primary resistance or relapse, followed by salvage conventional-dose chemotherapy.

All patients were treated in Maria Sklodowska-Curie Institute - Oncology Centre in Gliwice, Poland. All data used for the analysis were obtained based on patients' hospital files. Patients referred for autoHCT signed written informed consent forms to use their files for scientific purposes.

\section{Conditioning regimens and supportive care}

BEAM consisted of carmustine $300 \mathrm{mg} / \mathrm{m}^{2}$ given intravenously (IV) in a 2-h infusion with $500 \mathrm{~mL} 0.9 \% \mathrm{NaCl}$ on day -6 , etoposide $150-200 \mathrm{mg} / \mathrm{m}^{2}$ IV BID in 30-min infu-

Table 1. Patient characteristics

\begin{tabular}{|c|c|c|c|}
\hline & $\begin{array}{c}\text { BEAM } \\
n=174\end{array}$ & $\begin{array}{l}\text { BeEAM } \\
n=63\end{array}$ & $p$-value \\
\hline Age, median (range) & $46.5(19.5-69.4)$ & $45(21.5-72.8)$ & 0.91 \\
\hline $\begin{array}{l}\text { Gender, male (\%)/ } \\
\text { female }(\%)\end{array}$ & $\begin{array}{c}104(59.8) / \\
70(40.2)\end{array}$ & $\begin{array}{l}37(58.7) / \\
26(41.3)\end{array}$ & 0.89 \\
\hline $\begin{array}{l}\text { Diagnosis, } n \text { (\%): } \\
\text { HL } \\
\text { DLBCL } \\
\text { FL } \\
\text { MCL } \\
\text { MZL } \\
\text { BL } \\
\text { ALCL ALK+ } \\
\text { ALCL ALK- } \\
\text { PTCL NOS } \\
\text { EATL } \\
\text { LBL }\end{array}$ & $\begin{array}{c}85(48.8) \\
57(32.8) \\
8(4.6) \\
7(4.0) \\
3(1.7) \\
1(0.6) \\
1(0.6) \\
1(0.6) \\
2(1.1) \\
1(0.6) \\
0\end{array}$ & $\begin{array}{c}25(39.7) \\
20(31.7) \\
6(9.5) \\
3(4.8) \\
2(3.2) \\
0 \\
0 \\
0 \\
0 \\
0 \\
1(1.6)\end{array}$ & 0.54 \\
\hline $\begin{array}{l}\text { Remission status } \\
\text { before HSCT (\%): } \\
\text { CR1 } \\
\text { CR2 } \\
\text { CR }>2 \\
\text { PR1 } \\
\text { PR2 } \\
\text { NR/PD }\end{array}$ & $\begin{aligned} 70 & (40.2) \\
32 & (18.4) \\
2 & (1.4) \\
49 & (28.2) \\
2 & (1.1) \\
15 & (8.6)\end{aligned}$ & $\begin{aligned} 25 & (39.7) \\
7 & (11.1) \\
2 & (3.2) \\
18 & (28.6) \\
1 & (1.6) \\
10 & (15.9)\end{aligned}$ & 0.31 \\
\hline $\begin{array}{l}\text { CD34+ cell dose } \\
\left(\times 10^{6} / \mathrm{kg}\right), \text { median } \\
\text { (range) }\end{array}$ & $5.1(1.5-42.6)$ & $4.1(2.0-16.8)$ & 0.007 \\
\hline \multicolumn{4}{|c|}{$\begin{array}{l}\text { HL - Hodgkin lymphoma; } D L B C L \text { - diffused large B-cell lymphoma; } F L \text { - } \\
\text { follicular lymphoma; } M C L \text { - mantle cell lymphoma; } M Z L \text { - marginal zone } \\
\text { lymphoma; } B L \text { - Burkitt lymphoma; } A L C L A L K+\text { - anaplastic large T-cell } \\
\text { lymphoma } A L K \text {-positive; } A L C L A L K \text { - anaplastic large T-cell lymphoma } \\
\text { ALK-negative; PTCL NOS - peripheral T-cell lymphoma not otherwise } \\
\text { specified; } E A T L \text { - enteropathy associated T-cell lymphoma; } L B L \text { - lymphoblastic } \\
\text { lymphoma; } C R \text { - complete remission; } P R \text { - partial remission; NR - non- } \\
\text { remission; } P D \text { - progressive disease }\end{array}$} \\
\hline
\end{tabular}

sion with $500 \mathrm{ml} \mathrm{NaCl} 0.9 \%$ on days -5 to -2 , cytarabine $200 \mathrm{mg} / \mathrm{m}^{2} / \mathrm{d}$ IV BID in a 30-min infusion with $500 \mathrm{ml} \mathrm{NaCl}$ $0.9 \%$ on days -5 to -2 , and melphalan $140 \mathrm{mg} / \mathrm{m}^{2} \mathrm{IV}$ in a single 1-h $500 \mathrm{ml}$ infusion with $0.9 \% \mathrm{NaCl}$ on day -1 .

In the BeEAM group carmustine was replaced by bendamustine; the agent was administered on days -7 and -6 at the dose of $160-200 \mathrm{mg} / \mathrm{m}^{2} /$ day IV in a $2-\mathrm{h}$ infusion. Other cytostatics were given in the same way as in the BEAM protocol.

All patients received granulocyte - colony stimulating factor (G-CSF) at $5 \mathrm{ug} / \mathrm{kg}$ b.w. starting from day +4 after AHSCT until absolute neutrophil count reached $0.5 \times 10^{9} / \mathrm{l}$ for three consecutive days. All patients received antiviral (oral acyclovir), antifungal (oral fluconazole), and antibacterial (oral ciprofloxacin) prophylaxis. Since the start of conditioning until day 0 , hyperuricaemia prophylaxis was given (oral allopurinol $100 \mathrm{mg}$ TID). Substitution of platelets or red blood cells was given when platelet count was lower than $20 \times 10 \%$ I or haemoglobin level was lower than $80 \mathrm{~g} / \mathrm{l}$, respectively.

\section{Measurements and definitions}

CD34+ cell count was assessed using flow cytometry, as previously described [19]. Toxicities were graded using Common Terminology Criteria for Adverse Events (CTCAE 4.0). Engraftment was defined as the presence of neutrophils $>0.5 \times 10^{9} / \mathrm{l}$ for three consecutive days and platelets $>50 \times 10^{9} /$ with no need of substitution.

OS was defined as the time from autoHCT to death from any cause or last follow-up. PFS was defined as the time from autoHCT until first relapse/progression, death, or last follow-up. Remission status before autoHCT and at day 100 after the procedure was assessed using TK or 18FDG PET-TK imaging.

\section{Statistical analysis}

The probabilities of OS and PFS as well as engraftment were estimated using the Kaplan-Meier method. Log-rank test was used for comparison of both study groups. The frequencies of adverse events were compared using $\chi^{2}$ test. $P$-values $<0.05$ were considered statistically significant. Analyses were performed using Statistica Version 12 (Statsoft, Tulsa, OK).

\section{Results}

\section{Patients characteristics}

We analysed 237 patients, including 110 (46.4\%) with $\mathrm{HL}$ and 127 (53.6\%) with NHL. Among NHL subtypes the diagnosis of DLBCL predominated (89 patients). Clinical characteristics of both groups were comparable; they are summarised in Table 1. The median age at autoHCT was 46.5 years for BEAM and 45 years for BeEAM, respectively, with male predomination ( $59.8 \%$ and $58.7 \%$, respectively). Evaluation of the remission status before autoHCT revealed that 123 (70.6\%) patients treated with BEAM and 43 (68.3\%) individuals in the BeEAM group underwent the autoHCT procedure in first complete or partial remission preceded by one or more lines of conventional-dose chemotherapy. 


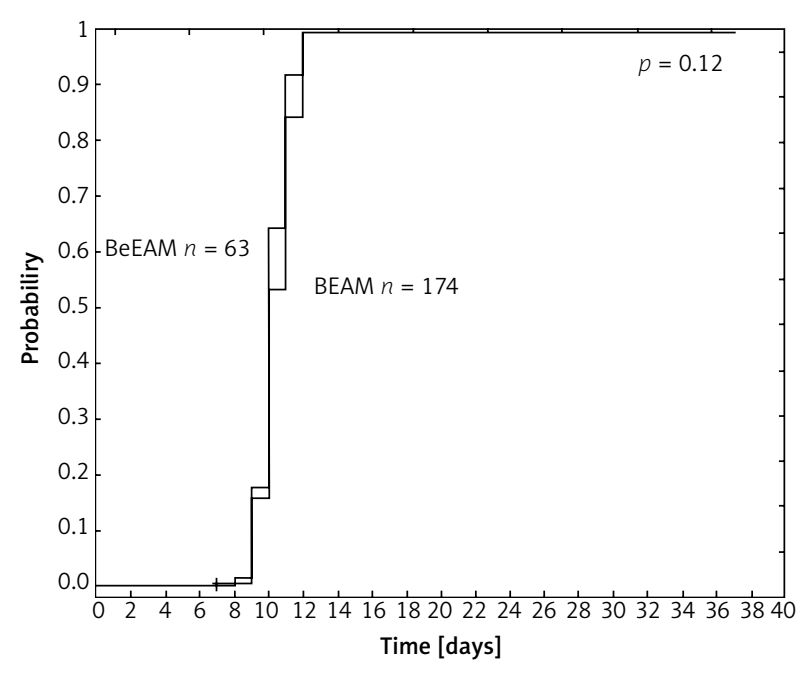

Fig. 1. Neutrophil recovery $>0.5 \times 10^{9} / 1$

The number of patients with stable or progressive disease was 15 (8.3\%) and 10 (15.9\%) in BEAM and BeEAM groups, respectively. The remaining patients entered the procedure in a phase of chemosensitive relapse. Peripheral blood was the source of stem cells in all cases, and the median of infused CD34+ cells was significantly higher in the BEAM compared to the BeEAM cohort (Table 1).

\section{Engraftment}

The kinetics of neutrophil and platelet recovery are illustrated in Figure 1 and Figure 2, respectively. Median time to neutrophil recovery was 10 days in both groups $(p=0.12)$. Median time to platelet count regeneration $>50 \times 10^{\%} / \mathrm{L}$ was 13 and 14 days after BEAM and BeEAM, respectively $(p=0.29)$.

Four $(1.7 \%)$ patients died in the early phase of the AHSCT, before haematological engraftment; three in the BEAM group (1.7\%) and one in the BeEAM group (1.6\%) $(p=0.94)$. In all cases the mortality was caused by infections; in three cases by severe pneumonia and in one case by septic shock.

\section{Adverse events}

Nausea grade 2-4 was the most common side effect, which occurred in $32.1 \%$ of patients treated with BEAM and $41.3 \%$ of patients treated with BeEAM, respectively ( $p=0.19$ ) (Table 2$)$. The rates of grade 3-4 nausea as well as grade 3-4 vomiting were comparable. Arterial hypertension and severe hypokalaemia occurred in two and three patients, respectively, all of them in the BeEAM group ( $p=0.02$ and $p=0.004$, respectively, for the comparisons with the BEAM group). Other non-haematological complications were incidental and did not differ significantly according to the type of conditioning regimen. Two cases of transient acute kidney injury (AKI) grade 2 were observed, one in each group; there was no need for dialysis in any case. Moderate cardiac arrhythmias (grade 2); supraventricular extrasystoles and atrial fibrillations were observed in three patients in the BEAM group. Mild and moderate metrorrhagia (grade 1 and 2) as well as allergic reaction

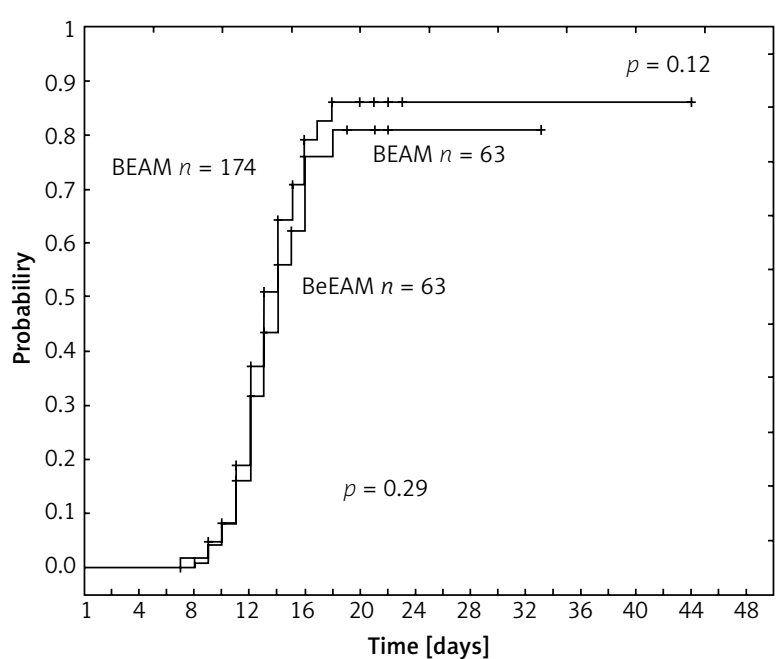

Fig. 2. Platelet recovery $>50 \times 10^{9} / 1$

Table 2. Side effects of conditioning regimen

\begin{tabular}{|c|c|c|c|}
\hline & $\begin{array}{l}\text { BEAM } \\
n=174\end{array}$ & $\begin{array}{l}\text { BeEAM } \\
n=63\end{array}$ & $p$-value \\
\hline $\begin{array}{l}\text { Nausea, } n(\%) \text { : } \\
\text { grade } 2-4 \\
\text { grade } 3-4\end{array}$ & $\begin{array}{l}56(32.1) \\
24(13.8)\end{array}$ & $\begin{array}{l}26(41.3) \\
7(11.1)\end{array}$ & $\begin{array}{l}0.19 \\
0.59\end{array}$ \\
\hline $\begin{array}{l}\text { Vomiting, } n(\%) \text { : } \\
\text { grade } 2-4 \\
\text { grade } 3-4\end{array}$ & $\begin{array}{l}22(12.6) \\
8(4.6)\end{array}$ & $\begin{array}{l}9(14.3) \\
2(3.2)\end{array}$ & $\begin{array}{l}0.74 \\
0.63\end{array}$ \\
\hline $\begin{array}{l}\text { Mucositis, } n(\%) \text { : } \\
\text { grade } 2-4 \\
\text { grade 3-4 }\end{array}$ & $\begin{array}{c}29(16.7) \\
11(6.3)\end{array}$ & $\begin{array}{c}11(17.5) \\
5(7.9)\end{array}$ & $\begin{array}{l}0.88 \\
0.66\end{array}$ \\
\hline $\begin{array}{l}\text { Diarrhoea, } n(\%) \\
\text { grade } 2-4 \\
\text { grade } 3-4\end{array}$ & $\begin{array}{l}26(14.9) \\
8(4.6)\end{array}$ & $\begin{array}{c}13(20.6) \\
4(6.35)\end{array}$ & $\begin{array}{c}0.3 \\
0.59\end{array}$ \\
\hline $\begin{array}{l}\text { Pneumonia, } n(\%) \text { : } \\
\text { grade } 2-4 \\
\text { grade } 3-4\end{array}$ & $\begin{array}{l}6(3.5) \\
3(1.7)\end{array}$ & $\begin{array}{l}2(3.2) \\
1(1.6)\end{array}$ & $\begin{array}{l}0.92 \\
0.94\end{array}$ \\
\hline $\begin{array}{l}\text { Febrile neutropaenia, } n(\%) \text { : } \\
\text { grade } 2-4 \\
\text { grade } 3-4\end{array}$ & $\begin{array}{l}36(20.7) \\
36(20.7)\end{array}$ & $\begin{array}{l}13(20.6) \\
13(20.6)\end{array}$ & $\begin{array}{l}0.99 \\
0.99\end{array}$ \\
\hline $\begin{array}{l}\text { Hypokalaemia, } n(\%) \text { : } \\
\text { grade } 2-4 \\
\text { grade } 3-4\end{array}$ & $\begin{array}{l}0(0) \\
0(0)\end{array}$ & $\begin{array}{l}3(4.8) \\
3(4.8)\end{array}$ & $\begin{array}{l}0.004 \\
0.004\end{array}$ \\
\hline $\begin{array}{l}\text { Arterial hypertension, } n(\%) \text { : } \\
\text { grade } 2-4\end{array}$ & $0(0)$ & $2(3.2)$ & 0.02 \\
\hline $\begin{array}{l}\text { Elevated liver enzymes, } n \text { (\%): } \\
\text { grade } 2-4 \\
\text { grade } 3-4\end{array}$ & $\begin{array}{l}3(1.7) \\
2(1.2)\end{array}$ & $\begin{array}{l}1(1.6) \\
1(1.6)\end{array}$ & $\begin{array}{l}0.94 \\
0.79\end{array}$ \\
\hline $\begin{array}{l}\text { Cardiac arrhythmias, } n(\%) \text { : } \\
\text { grade } 2-4\end{array}$ & $3(1.7)$ & $0(0)$ & 0.3 \\
\hline $\begin{array}{l}\text { Metrorrhagia, } n(\%) \text { : } \\
\text { grade } 2-4\end{array}$ & $8(4.6)$ & $0(0)$ & 0.08 \\
\hline $\begin{array}{l}\text { Allergic reaction, } n(\%) \text { : } \\
\text { grade } 2-4 \\
\text { grade } 3-4\end{array}$ & $\begin{array}{l}5(2.9) \\
2(1.2)\end{array}$ & $\begin{array}{l}0(0) \\
0(0)\end{array}$ & $\begin{array}{l}0.17 \\
0.39\end{array}$ \\
\hline $\begin{array}{l}\text { Kidney injury, } n(\%) \text { : } \\
\text { grade } 2-4\end{array}$ & $1(0.6)$ & 1 (1.6) & 0.45 \\
\hline
\end{tabular}


grade 2-4 occurred in eight and five patients, respectively, only in the BEAM group.

The rates of febrile neutropaenia were almost the same for both study groups: $20.7 \%$ after BEAM and 20.6\% after BeEAM. Four patients suffered from severe pneumonia (three cases in the BEAM group and one case in the BeEAM group); the complication was fatal in three cases.

\section{Long-term outcome}

The median follow-up for survivors was 29 months in the BEAM group and seven months in the BeEAM group. Probabilities of the OS at 24 months were 91\% (95\% confidence interval, 89-93\%) and 89\% (83-95\%), respectively $(p=0.73)$. PFS rates at 24 months were $81 \%(78-84 \%)$ and $76 \%(69-83 \%)$, respectively $(p=0.55)$.

\section{Discussion}

Although HDCT followed by autoHCT is considered the treatment of choice in chemosensitive RR lymphomas, the optimal conditioning regimen has not yet been defined. Regimens most frequently used in RR NHL are BEAM, CBV (cyclophosphamide, carmustine, etoposide), or total body irradiation-containing schedules, while in a setting of $\mathrm{HL}$, BEAM is considered standard [13].

Carmustine as a part of BEAM is associated with the risk of pulmonary toxicity manifested by interstitial pneumonia. In order to avoid this complication and potentially to increase the efficacy of the regimen, it has been proposed that bendamustine be used instead of carmustine. The efficacy and tolerance of BeEAM was initially evaluated by Visani et al., in a prospective study including 43 patients with $\mathrm{HL}$ and NHL. TRM was $0 \%$, while the $\mathrm{Cu}-$ mulative incidence of infectious complications was $60 \%$, without non-haematological serious adverse events. The study revealed that the new protocol was safe and effective, especially for heavily pretreated patients [5]. The updated follow-up at 41 months after transplant revealed $72 \%$ probability of PFS at three years [6].

Gilly et al. reported a retrospective cohort of 39 patients treated with BeEAM as conditioning prior to autoHCT. The most common grade 3-4 non-haematological toxicities comprised mucosal side effects (69\%). Pulmonary toxicity was observed in one patient (2.5\%), and one patient died of septic complications.

In the current study, for the first time the safety profile of BeEAM was compared with BEAM. The group of patients treated with BeEAM was the largest reported in the literature so far. The analysis revealed no differences in terms of neutrophil and platelet engraftment. Furthermore, the rate of infectious and non-infectious complications did not differ between groups, except of slightly more frequent incidence of hypokalaemia and hypertension in the BeEAM group compared to the BEAM group. Finally, the rate of early TRM was small and comparable for patients treated with BEAM and BeEAM, not exceeding $2 \%$ regardless of the type of the regimen.

According to a previous phase I study on patients with solid tumours, cardiac complications (such as supraventricular tachycardia, premature supraventricular complex- es, premature atrial complexes, ventricular extrasystoles) were among the most frequent toxicities associated with administration of bendamustine [20]. Cardiac toxicity may be of concern in the context of HDCT, especially for patients who had previously been heavily pretreated, including the use of anthracyclines. However, in our study no cardiac arrhythmias in the BeEAM group were observed, despite the use of a relatively high dose of bendamustine.

There is some controversy regarding the frequency of renal injury after BeEAM. According to Gilli's report the rate of renal dysfunction was $28 \%$, while Visani et al. have not reported this complication. In our study, only two patients experienced reversible renal dysfunction, one after BeEAM and one after BEAM.

Our study had some substantial limitations associated with its retrospective nature. The choice of conditioning was not random, but in some periods it was related to the current availability of particular drugs. In other cases, however, there could have been a pre-selection bias related to physicians' preferences. Furthermore, the follow-up for patients treated with BeEAM was short, not allowing us to investigate the incidence of late adverse events. Also, the long-term efficacy of the treatment could not be reliably assessed. Although survival analysis suggests comparable results for BeEAM and BEAM, further prospective studies focused on homogenous patient populations are needed to confirm this preliminary observation.

Nevertheless, results of our analysis provide no evidence of increased early severe toxicity of BeEAM as compared to BEAM, as well as no detrimental effect on engraftment. Therefore, we conclude that carmustine may be safely replaced by bendamustine in preparative regimens for patients with lymphoma referred for autoHCT.

The authors declare no conflict of interest.

\section{References}

1. Schmitz N, Pfistner B, Sextro M, et al. Aggressive conventional chemotherapy compared with high dose chemotherapy with autologous haematopoietic stem-cell transplantation for relapsed chemosensitive Hodgkin's disease: a randomized trial. Lancet 2002; 359: 2065-2071.

2. Philip T, Guglielmi C, Hagenbeek A, et al. Autologous bone marrow transplantation as compared with salvage chemotherapy in relapses of chemotherapy-sensitive non-Hodgkin's lymphoma. N Engl J Med 1995; 333: 1540-1545.

3. Gohil SH, Ardeshna KM, Lambert JM, et al. Autologous stem cell transplantation outcomes in elderly patients with B cell Non-Hodgkin Lymphoma. Br J Haematol 2015; 171: 197-204.

4. Mills W, Chopra R, McMillan A, Pearce R, Linch DC, Goldstone AH. BEAM chemotherapy and autologous bone marrow transplantation for patients with relapsed or refractory non-Hodgkin's lymphoma. J Clin Oncol 1995; 13: 588-595.

5. Visani G, Malerba L, Stefani PM, et al. BeEAM (bendamustine, etoposide, cytarabine, melphalan) before autologous stem cell transplantation is safe and effective for resistant/relapsed lymphoma patients. Blood 2011; 118: 3419-3425.

6. Visani G, Stefani PM, Capria S, et al. Bendamustine, etoposide, cytarabine, melphalan, and autologous stem cell rescue produce a 72\% 3-year PFS in resistant lymphoma. Blood 2014; 124: 30293031. 
7. Lane AA, Armand P, Feng Y, et al. Risk factors for development of pneumonitis after high-dose chemotherapy with cyclophosphamide, BCNU and etoposide followed by autologous stem cell transplant. Leuk Lymphoma 2012; 53: 1130-1136.

8. Till BG, Madtes DK. BCNU-associated pneumonitis: portrait of a toxicity. Leuk Lymphoma 2012; 53: 1019-1020.

9. Sellner L, Boumendil A, Finel H, et al. Thiotepa-based high-dose therapy for autologous stem cell transplantation in lymphoma: a retrospective study from the EBMT. Bone Marrow Transplant 2016; 51: 212-218

10. Ramzi M, Mohamadian M, Vojdani R, Dehghani M, Nourani H, Zakerinia M, Haghighinejad H. Autologous noncryopreserved hematopoietic stem cell transplant with CEAM as a modified conditioning regimen in patients with Hodgkin lymphoma: a single-center experience with a new protocol. Exp Clin Transplant 2012; 10: 163 167.

11. Bains T, Chen Al, Lemieux A, Hayes-Lattin BM, Leis JF, Dibb W, Maziarz RT. Improved outcome with busulfan, melphalan and thiotepa conditioning in autologous hematopoietic stem cell transplant for relapsed/refractory Hodgkin lymphoma. Leuk Lymphoma 2014, 55: 583-587.

12. Leoni LM, Bailey B, Reifert J, Bendall HH, Zeller RW, Corbeil J, Elliott G, Niemeyer CC. Bendamustine (Treanda) displays a distinct pattern of cytotoxicity and unique mechanistic features compared with other alkylating agents. Clin Cancer Res 2008; 14: 309-317.

13. Fischer K, Stilgenbauer S, Schweighofer CD, et al. Bendamustine in combination with rituximab (BR) for patients with relapsed chronic lymphocytic leukemia (CLL): a multicenter phase II trial of the German CLL study group [abstract]. Blood 2008; 112: Abstract 130.

14. Rummel MJ, Al-Batran SE, Kim SZ, et al. Bendamustine plus ritux imab is effective and has a favorable toxicity profile in the treatment of mantle cell and low-grade non-Hodgkin's lymphoma. J Clin Oncol 2005; 23: 3383-3389.

15. Robinson KS, Williams ME, van der Jagt RH, et al. Phase II multicenter study of bendamustine plus rituximab in patients with relapsed indolent B-cell and mantle cell non-Hodgkin's lymphoma. J Clin Oncol 2008: 26; 4473-4479.

16. Friedberg JW, Cohen P, Chen L, et al. Bendamustine in patients with rituximab-refractory indolent and transformed non-Hodgkin's lymphoma: results from a phase II multicenter, single-agent study. J Clin Oncol 2008; 26: 204-210.

17. Chen YB, Lane AA, Logan B, et al. Impact of conditioning regimen on outcomes for patients with lymphoma undergoing high-dose therapy with autologous hematopoietic cell transplantation. Biol Bone Marrow Transplant 2015; 21: 1046-1053.

18. Gilli S, Novak U, Taleghani BM, et al. BeEAM conditioning with bendamustine-replacing BCNU before autologous transplantation is safe and effective in lymphoma patients. Ann Hematol 2017; 96: 421-429.

19. Mitrus I, Smagur A, Giebel S, et al. A faster reconstitution of hematopoiesis after autologous transplantation of hematopoietic cells cryopreserved in $7.5 \%$ dimethyl sulfoxide if compared to $10 \%$ dimethyl sulfoxide containing medium. Cryobiology 2013; 67: 327-331.

20. Rasschaert M, Schrijvers D, Van den Brande J, Dyck J, Bosmans J, Merkle K, Vermorken JB. A phase I study of bendamustine hydrochloride administered day 1+2 every 3 weeks in patients with solid tumours. Br I Cancer 2007; 96: 1692-1698.

\section{Address for correspondence}

\section{Andrzej Frankiewicz}

Maria Sklodowska-Curie

Memorial Cancer Centre

and Institute of Oncology Gliwice Branch

15 Wybrzeże Armii Krajowej St.

44-101 Gliwice, Poland

e-mail: afrankiewicz@io.gliwice.pl

Submitted: 9.06 .2017

Accepted: $\quad 26.03 .2018$ 